\title{
Reference and Perception: Towards a Social Relativism Perspective
}

\author{
Jie Zhang ${ }^{1}$
}

Social Reference Theory postulates that each perception is based on a reference. No specific perception (knowledge, evaluation, etc.) could be realized without a reference; various perceptions of the same object may be obtained with different references. This theoretical conceptualization is initially based on some key notions in philosophy, psychology, economics, sociology, etc. The concept also has roots in certain aspects of Chinese culture and thoughts. When viewed in terms of social theories, this perspective differs from other major ones in Western sociology for both theoretical framing and methodologies, and has many practical implications in the social world. In this paper, I first discuss the principles of the concept and the previous notions that have led to the conceptualization. After an elaboration of the structure of the perspective, I provide some preliminary empirical evidence to support the theory. Finally, I illustrate and discuss selected macro and micro-level social psychology, criminology, and economics theories in comparison with Social Reference Theory as a sociological perspective. With further development and refinement along with empirical studies, this theory may hopefully become an additional theoretical perspective and methodology parallel to other major sociological theorems. [Article copies available for a fee from The Transformative Studies Institute. E-mail address: journal@transformativestudies.org Website: http://www.transformativestudies.org @2013 by The Transformative Studies Institute. All rights reserved.]

KEYWORDS: Sociology, Reference, Comparison, Perception.

\footnotetext{
${ }^{1}$ Jie Zhang, Ph.D., is Professor at Central University of Finance and Economics School of Social Development, Beijing, China and director of the Center for China Studies at State University of New York (SUNY) at Buffalo. He was educated in China (BA) and the USA (Ph.D.). He teaches social psychology and classical theories. He received awards for his teaching, research, and faculty service from both Buffalo State and SUNY. Besides theoretical sociology, Dr. Zhang's research interests are in the mental health and suicidal behaviors. He is currently the Principal Investigator for NIMH grants and has published in both English and Chinese with over 100 journal articles printed in top journals in the world. Address correspondence to: Jie Zhang, Department of Sociology, State University of New York College at Buffalo, 1300 Elmwood Avenue, Buffalo, New York 14222; Tel: 716-878-6425; Fax: 716-878-4009; e-mail: zhangj@,buffalostate.edu.
} 